Fanum

Sociológico
Forum Sociológico

Série II

23 | 2013

Número 23

\title{
Novas perspetivas sobre as identidades de classe
}

\author{
José Cavaleiro Rodrigues
}

\section{OpenEdition}

Journals

Edição electrónica

URL: https://journals.openedition.org/sociologico/813

DOI: 10.4000/sociologico.813

ISSN: 2182-7427

\section{Editora}

CICS.NOVA - Centro Interdisciplinar de Ciências Sociais da Universidade Nova de Lisboa

Edição impressa

Data de publição: 1 novembro 2013

Paginação: 41-49

ISSN: 0872-8380

\section{Refêrencia eletrónica}

José Cavaleiro Rodrigues, «Novas perspetivas sobre as identidades de classe », Forum Sociológico

[Online], 23 | 2013, posto online no dia 01 janeiro 2014, consultado o 29 março 2022. URL: http:// journals.openedition.org/sociologico/813 ; DOI: https://doi.org/10.4000/sociologico.813

Este documento foi criado de forma automática no dia 29 março 2022.

(c) CICS.NOVA 


\title{
Novas perspetivas sobre as identidades de classe
}

\author{
José Cavaleiro Rodrigues
}

1 A sociologia britânica integra, desde o final da última década do século XX, um movimento de renovação da análise das classes que, indo além das orientações mais tradicionais e dominantes nos debates sobre as estruturas de desigualdade, tem ensaiado abordagens que vêm enfatizar a importância dos referentes culturais na demarcação e reconhecimento de posições e o modo como as classes são vividas e experienciadas no dia-a-dia, em planos simultaneamente coletivos e individuais. Partindo de conceptualizações das desigualdades de classe nem sempre coincidentes, o que unifica este conjunto de autores é, antes de mais, situarem as suas análises na observação das práticas de interação quotidianas e nas representações vulgares dos sujeitos, facto que justifica a associação desta perspetiva à investigação daquilo que genericamente é apelidado de "identidades de classe".

O interesse por estas dimensões, ditas subjetivas, sempre existiu na sociologia das classes e da estratificação, ainda que as perspetivas prevalecentes no passado usassem linguagens e mantivessem objetivos distintos. A análise tradicional assentava num modelo "Estrutura-Consciência-Ação" (Savage, 2000: 26), em que as estruturas eram vistas como conduzindo a ação através de formas particulares de consciência de classe, o mesmo é dizer, pressupunha-se a necessidade da existência de grupos com a noção de si próprios e dos seus interesses e, portanto, a existência de identidades intermediando a relação entre condições estruturais e formas de ação. As grandes questões teóricas giravam em torno da consciência de classe, particularmente da consciência que os trabalhadores tinham da sua pertença a uma classe e da sua inserção numa estrutura de classes e, depois disso, em saber em que medida é que os mesmos trabalhadores se mobilizavam para defender os seus interesses de forma organizada. Dentro desta lógica, as identidades de classe figuravam menos como um problema autónomo do que como uma tradução empírica das questões de fundo colocadas pela consistência e coesão demonstradas pelas consciências de classe. 
3 É durante os anos 50 que nos surgem as primeiras investigações dedicadas especificamente às identidades e ao significado que as pertenças de classe tinham para a vida dos trabalhadores industriais e das suas famílias. Seguindo uma abordagem típica dos estudos de comunidade, estes trabalhos desenvolvidos em Inglaterra (Dennis e Henriques, 1970; Young e Willmott, 1983) procuravam identificar diretamente as marcas de classe em várias dimensões da vida quotidiana, desde as baixas remunerações do trabalho à precariedade dos alojamentos e à exiguidade de acesso a bens materiais, condições consideradas decisivas para o desenvolvimento de sentimentos e laços de solidariedade nos locais de trabalho e nas áreas de residência e para a existência de uma forte consciência operária e de oposição às classes proprietárias e aos seus modos de vida.

4 Não deixa de ser irónico o facto de estes estudos se realizarem exatamente no momento em que as estruturas produtivas e socioprofissionais europeias apresentavam sinais inequívocos de mudança. Eles permitem-nos hoje resgatar a memória de um operariado tradicional que começava a desaparecer e a ser substituído por um novo segmento de trabalhadores com mais qualificações, mais bem remunerados, cujo nível de vida fazia despertar aspirações ao consumo. Chegou-se a pensar na época que estes novos membros das classes trabalhadoras, por serem privilegiados relativamente aos seus antepassados, se veriam a si próprios como parte das classes médias, procurando emular os modos de vida do grupo que se estaria tornar a sua referência social. A "tese do aburguesamento", como ficou conhecida, foi posteriormente refutada pela análise sociológica, em particular por Goldthorpe e Lockwood em The Affluent Worker (1969). Nesta obra, os autores reconheciam a importância das mudanças sociais ocorridas, mas refutavam a suposta promoção da classe operária às classes médias, bem como a tentativa de explicar essa integração ligando-a ao crescimento da riqueza disponível. Para eles, as verdadeiras mudanças encontravam-se nos comportamentos e no imaginário das classes operárias, nomeadamente numa visão mais instrumental do trabalho que estaria ligada à alteração das condições laborais e numa certa privatização dos modos de vida, em resultado da melhoria dos padrões habitacionais. Assinalavam igualmente a tendência dos novos operários para diferenciar as classes de acordo com os níveis de rendimentos e os estilos de vida e para aplicarem esses mesmos critérios materialistas ao tratarem de se fazer incluir numa classe média alargada na qual reuniam todos os trabalhadores, sem respeitarem a divisão clássica entre trabalho manual e não-manual. Na sua visão das desigualdades não caberia a consciência de uma identidade e de interesses próprios, como acontecia com o operariado tradicional, mas sim uma valorização das aspirações materiais e a aceitação da ordem estabelecida.

5 The Affluent Worker foi uma obra controversa na época em que foi editada, mas acabou por se tornar um marco na investigação sobre as classes sociais. Nos anos que se lhe seguiram, as investigações produzidas na sua senda reforçaram as dúvidas sobre a capacidade de os membros das classes trabalhadoras defenderem uma imagem clara e consistente do conjunto da estrutura de classes e da posição por si ocupada nessa estrutura, enquanto, simultaneamente, se ia instalando a convicção entre os especialistas de que a ambivalência seria o traço definidor do posicionamento dos trabalhadores face às desigualdades e aos sistemas sociopolíticos que as sustentam. Na opinião de autores como Devine (2004: 194), o consenso gerado acerca da ambivalência das classes trabalhadoras justificaria só por si o impasse em que se caiu desde então no estudo da consciência de classe. Dos finais dos anos 80 a esta parte, o debate é 
definitivamente reorientado pela passagem para primeiro plano do conceito de identidade e pela incerteza sobre a relevância que as classes continuam ou não a ter enquanto base para a identificação social.

6 A década de 80 mal tinha começado quando, de fora da área de especialidade, começaram a fazer-se ouvir os primeiros ecos de teses que proclamavam o declínio das identidades de classe. Segundo estas teorizações, o enfraquecimento das identidades fundadas nas pertenças de classe seria um dos aspetos fundamentais das profundas transformações sociais e culturais contemporâneas que decorreriam da ultrapassagem histórica do antigo paradigma de relações das sociedades capitalistas e industriais. Entre os autores que defendem o ponto de vista da passagem a uma nova fase da modernidade, uma "modernidade líquida", ou o advento de uma "modernidade tardia", temos, respectivamente, Bauman e Giddens. Não fazendo propriamente parte de uma mesma corrente de pensamento, os dois sociólogos pouco têm em comum além de prognosticarem a chegada de um tempo de dissolução dos referenciais de classe. Vejamos, separadamente, algumas das ideias que propõem.

7 Bauman $(1982 ; 1989)$ identifica a individualidade e a liberdade como valores matriciais da modernidade, necessidades estabelecidas por um contexto societário em que "tendo quebrado todas as grilhetas que amarravam as pessoas quase definitivamente a posições impostas, os tempos modernos encontram indivíduos com a tarefa cruciante de construírem a sua própria identidade social" (1989: 101). Com a passagem à modernidade tardia, verifica-se uma nova expansão das condições de liberdade em que se processa a autoafirmação pessoal, facto que, na perspetiva do autor, resulta da transferência da competição identitária da área da produção material para a esfera do consumo. A competição que decorre através das atividades de consumo é mais livre porque, podendo continuar a envolver objetos materiais, se joga sobretudo no domínio simbólico: o que está em causa, mais do que a simples posse de bens, é a distinção proporcionada pelos símbolos de prestígio que se conquistam.

8 A este nível, há alguma compatibilidade entre as propostas de Giddens (1992; 1994) e as de Bauman. Temos de novo as condições impostas pela ordem pós-tradicional da modernidade líquida como pano de fundo sobre o qual decorrem as transformações nas formas de estruturação da identidade pessoal, mas a palavra-chave para entender estes processos é agora "reflexividade". Ou seja, perante contextos sociais em que se multiplicam as opções possíveis, crescem em número e complexidade os riscos que têm de ser avaliados e filtrados através da mobilização de sistemas abstratos e do conhecimento pericial, tarefas que exigem da parte dos indivíduos um "planeamento da vida organizado de modo reflexivo" (1994: 5). As escolhas que reflexivamente há que realizar são entre estilos de vida, uma vez que, segundo Giddens, "por causa da «abertura» da vida social de hoje, da pluralização de contextos de ação e da diversidade de «autoridades», a escolha de um estilo de vida tem uma importância crescente na constituição da autoidentidade e da atividade quotidiana" (1994: 5).

9 Tanto Giddens como Bauman reconhecem e tentam enquadrar as antigas formas de desigualdade material nas suas teorias de formação da identidade, mas fazem-no de uma forma que não é completamente esclarecedora. Para Giddens, "as divisões de classe e outras linhas fundamentais de desigualdade, tais como as que se relacionam com o género ou a etnicidade, podem em parte ser definidas em termos de acesso diferenciado a formas de autorrealização e capacitação" (1994: 5). Mesmo os pobres, impossibilitados de escolher estilos de vida, não estariam absolutamente fora do 
sistema, uma vez que "estilo de vida" se refere também "a decisões tomadas e cursos de ação seguidos em condições de constrangimento material extremo" (1994: 5). A autonomia concedida ao projeto reflexivo do self cria uma tensão face às determinantes das estruturas de desigualdade que Giddens não resolve, deixando de algum modo a impressão de que a busca e a manipulação expressiva de estilos de vida pode recobrir e absorver os traços das pertenças de classe e étnicas, ou mesmo os marcadores de exclusão, na formulação de identidades.

Quanto a Bauman, a estabilidade das conclusões não disfarça indícios contraditórios que ficam por clarificar na análise. A sua caraterização inicial do mercado de consumo como um espaço de liberdade "que pode ser usado por toda a gente" (1989: 102), onde "todos os fregueses podem ser ganhadores ao mesmo tempo", porque "as identidades não são bens escassos" (1989: 103), é desmontada e negada posteriormente quando introduz na análise os pobres. 0 estado de pobreza absoluta dos materialmente destituídos corresponde a uma condição social de exclusão "causada principalmente pela inaptidão para desempenhar o papel de consumidor, e depois confirmada, legalmente corroborada e burocraticamente institucionalizada, como condição de heteronomia e de não-liberdade" (1989: 136). Estes pobres veem-se privados da liberdade de se afirmarem através do consumo e, simultaneamente, condenados a viverem com uma identidade diminuída e a "procurar refúgio em casa, que passa a servir de sítio que protege da ameaça real ou imaginária da condenação comunal, do ridículo ou da compaixão" (1989: 137). Mas a pobreza é uma situação muito mais abrangente na sociedade de consumo. Aos primeiros, pobres "reprimidos", juntam-se todos os "seduzidos", aqueles que terão sempre muito menos do que aquilo que desejam e que transformam "a esmagadora maioria do resto da população em «subjetivamente pobre»" (1989: 155). Finalmente, e ao contrário do que se poderia esperar, o consumo para Bauman não cria uma sociedade de indivíduos livres e autónomos, antes redireciona e restringe a competição identitária e torna a liberdade um privilégio de poucos. Desaparecidas as classes, persistem as desigualdades no tempo da modernidade líquida. A sociedade é agora estratificada pelo consumo e a liberdade de escolha - ou a sua ausência - torna-se o critério de colocação nas hierarquias, de definição das identidades sociais e da exclusão de grande parte dos consumidores.

Ao mesmo tempo que Giddens e Bauman publicavam estas teses, outras vozes, provenientes de quadrantes diversos, repetiam com argumentos próprios a mesma ideia do fim das classes, chamando a atenção quer para a desatualização ou exaustão do conceito (Pahl, 1989), quer para o desaparecimento das classes enquanto principal fator de ação coletiva (Pakulski e Waters, 1996). Na sociologia das classes estas interpelações mais não geraram no imediato do que acusações de inconsistência e a denúncia do caráter antagonista dos seus autores face à teoria das classes. Argumentos mais substanciais, da parte daqueles que continuam a acreditar que as desigualdades de classe constituem ainda hoje um dos principais fatores de estruturação das relações sociais, hão de aparecer mais tarde, sobretudo no quadro de um processo alargado de discussão em torno do conceito de classe e da necessidade de redirecionar a sua análise e encontrar novas manifestações da sua presença e intervenção nas sociedades contemporâneas (Savage, 2000; Skeggs, 2004; Atkinson, 2007; 2008). 


\section{A questão do apagamento identitário das classes} ótica são Marshall (1988) e Devine (1992). Separadamente, ambos detetam a presença entre os trabalhadores britânicos de representações muito fortes acerca da existência de divisões de classe na sua sociedade e a capacidade para identificarem com maior ou menor clareza as posições de classe por si ocupadas. No caso de Marshall as identificações são firmes, enquanto no de Devine se revelavam alguns sinais de ambiguidade, patentes nos sentimentos de desconforto em relação ao tema das classes ou dos estatutos a elas associados, bem como na descrição da estrutura de classes em termos de riqueza ou níveis de vida. As identidades retratadas apresentavam ainda como traço comum o seu prolongamento na esfera política, através das tendências de voto e na maior proximidade em relação a determinadas forças políticas e sindicais, mas não davam origem a formas mais ativas de mobilização. Estes dados provaram aos olhos destes investigadores que, apesar das profundas transformações socioeconómicas registadas durante a segunda metade do século, as classes mantinham toda a atualidade como fator poderoso de identificação para os trabalhadores. Mesmo os sinais, por vezes percetíveis, de ambivalência nas identificações poderiam ser justificados pela natureza fraturada e conflitual de tudo o que é do domínio político nas sociedades pluralistas e democraticamente regidas.

Os resultados apresentados por Devine e Marshall viriam a ser contraditados meia dúzia de anos mais tarde. Estudos sucessivos publicados nos últimos anos da década de 90 (Skeggs, 1997; Reay, 1998a; 1998b; Savage, 2000) revelaram atitudes, por parte dos inquiridos, invariavelmente ambíguas em relação às categorias de classe, e relutância em reclamar ou assumir com firmeza qualquer identidade de classe. Embora não tivessem dificuldade em reconhecer a persistência de dimensões de desigualdade ou em se prenunciarem sobre as classes de um ponto de vista político, resistiam quando se tratava de definir a sua própria posição e chegavam, em alguns casos, a recusar qualquer tipo de identificação. No primeiro dos estudos mencionados (Skeggs, 1997), a população estudada tem a particularidade de ser composta por jovens mulheres trabalhadoras e, ao introduzir a variável género, remete-nos também para esse outro nível de constrangimento representado pela condição feminina e para o modo como o mesmo afeta as perceções de classe. Segundo a autora, as mulheres com quem trabalhou procuravam dissimular ao máximo a sua pertença à classe trabalhadora, na presunção de que os estigmas e as imputações de caráter moral que, de acordo com as suas representações, incidiam sobre esta categoria resultariam inevitavelmente em prejuízo identitário para quem se dispusesse a assumir essa condição. 0 distanciamento em relação à classe de pertença objetiva era construído por meio de sinais de respeitabilidade que podiam ser acumulados em diferentes domínios, investindo na maneira de vestir, na decoração das casas e na educação dos filhos. Ainda que estes comportamentos remetessem diretamente para a influência de um grupo de referência concreto, as mulheres repudiavam igualmente a identificação com as classes médias, que apelidavam de pretensiosas. O que subjaz a esta projeção identitária não é uma 
vontade frustrada de se verem confundidas com a classe média, mas o desejo da parte das mulheres de conquistarem a valorização e o respeito com os quais a patologização da classe trabalhadora é manifestamente incompatível. A autora é categórica quanto a este aspeto: "As mulheres podem desidentificar-se relativamente à classe trabalhadora mas isto não significa que queiram assumir por completo a pertença à classe média" (Skeggs, 1997: 93). Estaremos, assim pensa Skeggs, perante uma atitude que é de ordem política, de oposição às arbitrariedades das categorizações sociais, mas que simultaneamente prova como nas lutas pela identidade não é possível escapar ao poder das classes.

15 Num segundo trabalho, da autoria de Reay, encontramos relatos e uma análise largamente coincidentes com Skeggs. A abordagem às relações entre mulheres e classes sociais é feita, neste caso, por um ângulo particular que tem que ver com o envolvimento das mães na educação escolar dos filhos. Numa amostra mista, constituída por mulheres de classe trabalhadora e de classe média, as identificações em termos de classe constroem-se indiretamente através de discursos de identidade e diferença, que se servem, por exemplo, do tema da patologização de certos comportamentos e grupos para marcarem posições. Opções mais claras de autoidentificação só surgem, na maioria dos casos, quando solicitadas de modo explícito e adotam a mesma linguagem de distinção entre "pessoas como nós" e "pessoas diferentes de nós". É à mesma terminologia que se recorre para dar conta da incapacidade em lidar com a instituição escolar e tirar partido dos recursos que distribui: "a maioria das mães da classe trabalhadora e das mães que tendo origem na classe trabalhadora se consideravam da classe média ou sem classe usavam a retórica de «pessoas como nós» para narrativamente criarem uma imagem contrastante de outros mais privilegiados e deste modo explicarem porque é que lhes podia ser negado o sucesso escolar que tanto desejavam para as suas crianças" (Reay, 1998b: 269). Sem que a palavra "classe" seja nomeada, os discursos deixam perceber que são as identidades diminuídas, a noção da falta de recursos materiais e culturais e os sentimentos de ausência de poder que influenciam as atitudes e a interação das mães trabalhadoras com as escolas. Estas atribuições quotidianas de sentido com impacto na escolaridade são consideradas parte dos processos de classe e um elemento que demonstra como e até que ponto as classes trabalhadoras se podem ressentir das suas fragilidades identitárias.

Do ponto de vista das identidades de classe, novos casos observados por Savage vêm reforçar os relatos anteriores. O trabalho de Savage é particularmente elucidativo porque reúne num único estudo quatro aglomerados urbanos diferentes, todos de classe média, nos quais a larga maioria da população ou não atribui a si própria uma posição de classe, ou resiste à ideia e acaba por se definir de um modo hesitante. Aqui, os comportamentos defensivos e a procura de distanciamento em relação às classes traduzem-se no modo como os entrevistados se classificam como "pessoas normais", isto independentemente de nalguns casos considerarem que fazem parte das classes médias e noutros se reverem nas classes trabalhadoras. 0 mais importante não será a maneira como "se definem a si próprios em termos de classe: o que lhes interessava enfatizar era serem "pessoas normais»" (Savage, 2000: 116). As classes continuam a afetar a autoidentificação, mas agora de outra forma, uma vez que

"as pessoas veem as classes como uma ameaça que polui a sua «normalidade». A «normalidade» é também vista como uma construção relacional a partir da qual se estabelecem contrastes com outros que estão colocados acima e abaixo de nós 
próprios. O termo «classe» pode ser usado neste contexto como uma categoria que

as pessoas empregam para se diferenciarem de outras pessoas" (2000: 116). reivindicam será uma maneira indireta de repudiar a atribuição de identidades de classe, uma vez que esta "coloca a possibilidade de as pessoas não serem verdadeiros indivíduos mas produtos de uma localização social" (2001: 890). Nesta investigação, referências mais seguras e confiantes às identidades de classe apareciam apenas em grupos minoritários cuja trajetória de vida tinha afastado para longe dos lugares de origem. Geralmente, eram grupos de inquiridos do sexo masculino, de classe média segundo os seus atributos objetivos, com percursos de mobilidade, que, contra a regra, manifestavam abertamente o seu orgulho de ter pertencido às classes trabalhadoras. Embora excecional, esta atitude mais livre para jogar, de um modo reflexivo, com as etiquetas de classe revaloriza as representações em torno da identidade da classe trabalhadora e da sua força moral, factos inesperados se recordarmos as imagens de decadência e de sujeição às condenações de outras classes que dominavam outras leituras sociológicas já aqui referidas, mas que se compreende face à segurança ontológica garantida pela ascensão social dos protagonistas.

Sumariámos até aqui algumas pesquisas representativas de uma nova geração de análises das subjetividades de classe e vimos como, neste e noutros estudos que poderiam também ser citados (Bradley, 1996), se assinala uma tendência para que os indivíduos adotem atitudes defensivas ou ambíguas face às identidades de classe, não assumindo abertamente filiações identitárias que tenham por base essas categorias. $O$ que passaremos a fazer de seguida é analisar as implicações destas descobertas, primeiro ao nível das tentativas mais elaboradas de interpretar o fenómeno da desidentificação e, segundo, vendo o que estas teses renovadoras significam para o conceito e para a teoria constituída das classes sociais.

\section{Desidentificação e reteorização das identidades de classe}

Se tomarmos as perplexidades e as recusas reiteradas nos discursos como prova de que as classes deixaram de figurar como princípio definidor das identidades na consciência dos indivíduos, temos de admitir que a desidentificação coloca um problema à análise das classes. Como justificar então o paradoxo representado por sociedades em que a persistência das desigualdades não é acompanhada por reações conscientes ou, pelo menos, por uma perceção identitária dos interesses de cada condição estrutural? De que modo pode a teoria das classes incorporar o aparente apagamento das identidades de classe nos indivíduos?

É preciso começar por dizer que nenhum dos autores citados, que verificaram o fenómeno de desidentificação, se dispõe a admitir que ele seja uma manifestação de processos que possam estar a pôr em causa a continuidade das classes. Antes pelo contrário, a desidentificação é vista como representando sob novas formas o prosseguimento dos processos de classe. Quando as mulheres de Skeggs e as de Reay sentem necessidade de contestar ou de dissimular as suas identidades, o que, segundo estas autoras, elas estão a fazer é a reagir a construções de respeitabilidade que, ao desvalorizarem e estigmatizarem as culturas de determinados grupos, se revelam enquanto processos decorrentes das oposições entre as classes. Em Savage, o 
apagamento das marcas das classes trabalhadoras nas identidades masculinas, de homens que fizeram parte desse grupo, merece uma explicação semelhante. 0 comportamento só ocorre, diz-nos, porque a associação das classes trabalhadoras a atributos positivos foi destruída a partir do momento em que as mudanças organizacionais tornaram $o$ trabalho manual dependente $\mathrm{e}$ subordinado, reposicionando socialmente os seus protagonistas. As identidades de classe estão hoje, como sempre estiveram, dependentes de processos históricos, de lutas pela imposição de significados e de mudanças nas relações de força entre as classes. A desidentificação é uma manifestação observável desses processos, dependente da vontade (ou da ausência de vontade) de determinadas classes em afirmarem ou tornarem visíveis as suas identidades, de acordo com o momento por que passam as suas relações com outros grupos de desigualdade.

21 Mas, se não se manifestam pela ação, nem são exteriorizadas discursivamente, de que modo continuam as classes e as identidades vivas nos comportamentos e nas atitudes? Sigamos a pista de Reay, que nos diz que "a classe é produzida numa dinâmica complexa entre classes, com cada classe a representar para as outras classes o "Outro»" (2005: 14) e recordemo-nos de que, em muitos dos depoimentos prestados aos vários investigadores, os entrevistados respondiam aos pedidos para identificarem a classe a que pertenciam classificando-se como "pessoas normais" ou falando de "pessoas como nós" para se distinguirem de outros que seriam "pessoas diferentes de nós". No lugar de filiações com agrupamentos de classe identificados, temos então comparações relacionais com "outros tipificados" ou o que Bottero também chama "um sentido relacional de distâncias sociais dentro de uma hierarquia" (2004: 990). Estas identidades relacionalmente estabelecidas podem recorrer a formas lexicais menos transparentes para se exprimirem, mas as diferenças e as desigualdades a que fazem referência para se localizarem no espaço social são em larga medida as mesmas das classes tradicionais. Quando as classes são o tema da entrevista ou estão implicadas no assunto em discussão, a distinção entre "nós" e "eles" envolve invariavelmente aspetos de status e de hierarquia, questões de superioridade e inferioridade material e moral, de julgamento sobre o valor social dos comportamentos. O desaparecimento das referências diretas às classes nas entrevistas bem como nos discursos quotidianos é interpretado como um sinal de que a ação das classes se tornou silenciosa e surge agora codificada em termos distintos.

o conjunto destas propostas renovadoras da análise das classes que temos estado a analisar é fortemente influenciado por Bourdieu e pela sua tese de que as lutas de classe se travam também ao nível simbólico e que os processos culturais de classificação são essenciais nessa relação de forças e na disputa de posições dentro do espaço social. Por exemplo, a proposição segundo a qual os sujeitos não precisam de nomear ou reconhecer as classes para que elas estejam presentes nas suas interações quotidianas, nos processos institucionais ou nas lutas pela identidade parece inspirada pelo conceito de gosto de Bourdieu e pela ideia de que a sua eficácia social resulta do facto de funcionar de modo inconsciente, a um nível em que escapa ao escrutínio da vontade (1979). Do mesmo modo que para Bourdieu as desigualdades são reprodutíveis por meio de meras preferências culturais, também outras práticas banais, aparentemente destituídas de significado especial, podem estar implicadas na reprodução das classes sociais e na hierarquização dos indivíduos. Estas formas de ação podem portanto contribuir para o posicionamento social dos indivíduos e construir-lhes identificações 
tácitas de classe, sem que essa referenciação dependa da existência de identidades de classe rigorosamente definidas na ação e reconhecíveis pelos discursos dos atores.

É possível ir ainda mais longe na busca de influências e encontrar em alguns dos estudiosos das identidades de classe as marcas do pensamento dos paradigmas fundadores da teoria das classes. Disso mesmo são exemplo Skeggs e Reay, que, ao considerarem a desidentificação das classes trabalhadoras e o colapso das suas formas de ação coletiva uma consequência das estratégias prosseguidas pelas classes dominantes, denunciam abertamente o comprometimento das suas grelhas de leitura com a teoria marxista clássica. A linguagem do conflito de classes, sobretudo quando exacerbados os seus significados coletivos, coloca-nos perante o contrassenso de nos fazer regressar a uma conceção coletiva, explícita e categorial, própria dum tempo em que as classes surgiam como entidades mobilizadoras e referências determinantes dos processos históricos. Foi para dar conta de outro tempo em que as classes se tornaram mais discretas, e a reprodução das desigualdades e dos privilégios passou a decorrer também numa lógica de diferenciação segundo processos tácitos e individualizados, que todo este movimento de reteorização das classes se iniciou.

Entre a nova geração de autores surgiram igualmente propostas, com um caráter programático mais definido, que, por colocarem a identidade cultural no centro da teoria das classes, reconhecem, desde logo, a impossibilidade de manter os antigos arquétipos. Referimo-nos à "análise culturalista das classes", alternativa avançada por Devine (Devine e Savage, 2000) e Savage (2000) e mais tarde subscrita por Bottero (2004, 2005), na senda de propostas inicialmente formuladas por Bourdieu em La Distinction (1979). Ao contrário dos antigos modelos, que pressupunham serem as estruturas de desigualdade e as classes economicamente definidas a dar origem às diferenças culturais e de estatuto, as premissas de Devine e Savage apontam para uma análise que pretende incidir sobre o modo como os processos culturais estão embebidos em tipos específicos de práticas sociais e económicas. Savage não podia ser mais claro acerca das suas intenções do que quando afirmou que o seu projeto era tratar "a análise das classes como um modo de análise cultural" (2000: 149), o que, em termos operatórios, obriga a identificar um ou vários contextos da vida social e ver como neles se produzem e reproduzem quotidianamente processos de desigualdade que envolvem, em simultâneo, práticas económicas e culturais. A fusão dos elementos culturais e económicos dispensa a existência de consciências ou identidades formadas pelas classes enquanto entidades coletivas, assim como a presença de conjuntos de disposições culturais uniformes; o que estabelece a relação entre classe e cultura é o modo como os aspetos culturais estão implicados em formas de exclusão e dominação que são simultaneamente simbólicas e materiais.

Do mesmo modo, os indivíduos não têm de reconhecer classes ou identificarem-se com grupos ou categorias de classe para que os processos de classe tenham lugar e as identidades se exprimam. Cada localização de classe deixou de fornecer aos seus membros uma identidade coletiva, o que transfere para os sujeitos o papel de definir as suas identidades, recorrendo a processos que forçosamente envolvem a comparação e o confronto com membros de outras classes sociais. Savage vê nessa individualização de processos, que até aqui eram coletivos, um dos aspetos mais radicais da reestruturação contemporânea do modo de atuação das classes. A outra transformação que destaca e à qual chama "o paradoxo da classe" (2000: xii) deriva do facto de, apesar de as desigualdades económicas e sociais continuarem extremamente marcadas, as pessoas 
não serem capazes de reconhecer a importância estrutural que as classes têm nas suas vidas.

Bottero concorda com Savage e Devine na conceptualização geral que estes autores apresentam duma análise culturalista das classes, mas acrescenta-lhe uma visão hierárquica que, segundo ele, corresponde mais de perto ao modo como as desigualdades funcionam no nosso tempo, além de marcar uma rutura com a versão oposicional do conceito tradicional de classe social: "Os processos individualizados e implícitos das desigualdades posicionais são mais bem descritos como estratificação social ou hierarquia. Mas, qualquer que seja a nossa linguagem, é importante reconhecer que as questões colocadas pela hierarquia se estendem bastante para além das que emergem das classes" (2004: 1000). Como se pode ver, e à imagem do que já aconteceu com as versões da teoria da desidentificação de Skeggs e Reay, também Bottero nos confronta com as velhas clivagens da análise das classes, marxistas e weberianas.

Um dos ganhos em representar as classes como ordem hierárquica é, defende Bottero, tornar mais compreensíveis os motivos que levam à invisibilidade de processos que estão tão presentes na nossa vida e que são tão decisivos nas oportunidades de que dispomos, nos estilos de vida que desfrutamos e no sentido que damos à nossa identidade e à dos outros. Se não temos uma maior consciência reflexiva das identidades, uma das razões reside na própria natureza hierárquica das diferenciações, isto é, na existência de múltiplos estratos sobrepostos e divididos por fronteiras que nem sempre são nítidas. Num estudo de Southerton (2002) sobre as fronteiras identitárias de três grupos residentes numa pequena cidade suburbana inglesa, descobriu-se que as narrativas de identificação de grupos, um "nós" e um "eles", se formavam com base na partilha de práticas e de orientações relativas à vida quotidiana que seguiam grosso modo linhas de divisão de classe. No entanto, as identificações não eram perfeitas, porque apesar de níveis de recursos similares ordenarem internamente as práticas, os valores e as atitudes, estas unidades subdividiam-se e interpenetravamse em virtude "de a localização residencial dentro da cidade (também fruto da mobilidade geográfica) constituir um «mundo social» que fornecia o terreno para perceções sobre a reputação, a competência e as convenções, dando substância e reforçando as categorizações sociais genéricas relacionadas com as caraterísticas de classe" (Southerton, 2002: 191). As identificações estavam, neste caso assim como estarão em muitos outros, baseadas em categorizações de classe, mas o reconhecimento interno de subgrupos somava a esse fator os elementos de status que resultavam da organização social local.

Acabámos de ver como a sobreposição do status à classe fluidifica as divisões entre estratos e complexifica a sua identificação, mas a representação hierárquica das classes indica-nos outros fatores para alargar a compreensão da tendência para a invisibilidade das identidades. Depois de produzidas, as hierarquias mantêm-se e são reproduzidas no âmbito de todo o tipo de atividades que preenchem o quotidiano dos indivíduos e em relação a muitas das quais não há nem a intencionalidade nem a perceção imediata de que delas resultem lutas de posicionamento, ou que tenham consequências para a identificação dos indivíduos participantes. "Uma vez que as hierarquias estão embebidas nas relações sociais mais íntimas, e «localização social» e «cultura» estão unidas pela natureza estruturada das práticas sociais correntes", desde que os indivíduos limitem as suas interações e estilos de vida aos padrões que os seus lugares 
hierárquicos definem, "as práticas hierárquicas surgem como "segunda natureza», irrelevantes e vulgares" (Bottero, 2004: 995).

Bottero dá uma atenção particular ao domínio relacional, nomeadamente ao mapeamento das interações entre parentes, amigos e outros parceiros, convencido de que "diferentes padrões de associação e estilo de vida constituem a estrutura da estratificação social", ou seja, que é no âmbito destas relações próximas que se jogam vantagens sociais hierárquicas e se "revelam padrões maiores de desigualdade" (Bottero e Prandy, 2003: 178). Esta posição vem ao encontro da ideia de que a reprodução das hierarquias se faz dentro de círculos sociais e que é a partir das atividades mundanas que as desigualdades se concretizam e adquirem continuidade, mas ao fazê-lo, e ao localizar nos momentos mais vulgares da vida social a reprodução das desigualdades, volta a salientar a natureza quase mecânica e porventura impercetível dos atos para os atores que lhe dão forma. Já uns anos antes, Savage, refletindo sobre a instalação de uma cultura individualista, se havia referido a um dispositivo de "deflexão lateral" com efeitos em tudo idênticos na criação de "uma sociedade que rotineiramente reproduz a desigualdade social ao mesmo tempo que deflete a atenção dos seus agentes lateralmente e não para cima e para baixo, tornando assim a questão da desigualdade social largamente «invisível» e, de algum modo, «desinteressante»" (2000: 159).

Os anos decorridos e o volume de trabalho produzido desde que esta geração de autores relançou a análise das identidades de classe permitem-nos fazer alguns balanços e identificar consensos. Um primeiro ponto de convergência é o de que, numa sociedade em que as desigualdades conservam toda a relevância estrutural, as antigas identidades de classe dão sinais de enfraquecimento. Maioritariamente os indivíduos mostram-se retraídos quando se trata de definir explicitamente a sua pertença a uma classe, mas a ambiguidade e o modo defensivo como se expressam está relacionado com o relativo enfraquecimento das classes enquanto entidades coletivas, e não com o reconhecimento da ligação da sua condição a uma posição particular dentro de um espaço ordenado de desigualdades. Segundo aspeto consensual, o apagamento das antigas identidades de classe não significa que as classes deixem de ser importantes para a definição das identidades individuais; o que acontece é uma transmutação das identidades de classe que se modificam na sua natureza e formas de manifestação. A importância das classes passa a revelar-se sobretudo no domínio mais restrito da ação e das atitudes quotidianas dos indivíduos face ao mundo e às relações sociais. É esta fonte de expressão codificada e subterrânea que permite reconhecer a vitalidade contemporânea das identidades de classe, mesmo quando elas não são expressamente nomeadas. O que mudou foi portanto a natureza das identidades de classe: deixaram de ser identidades coletivas, explícitas e oposicionais, para passarem a existir sob uma forma individual, implícita e relacional.

31 É certo que classes sociais nunca determinaram em absoluto as identidades no passado e não há nenhuma razão para acreditar que elas o estejam a fazer no nosso tempo, mas permanecem um instrumento privilegiado para o estudo das identidades dos indivíduos e da sua relação com o mundo social. Através dos significados que lhes são atribuídos, das subtilezas e variações discursivas com que se manifestam, das apreciações e perceções que as sustentam, as classes sociais continuam a demonstrar todo o seu poder e eficácia sobre a ação dos indivíduos, convertendo em classificações e distinções 
subjetivas a desigualdade de posições, de condições materiais e de oportunidades, com que constrangem a vida nas sociedades contemporâneas.

\section{BIBLIOGRAFIA}

ATKINSON, W. (2007), “Anthony Giddens as adversary of class analysis”, Sociology, 41 (3), pp. 533-549.

ATKINSON, W. (2008), "Not all that was solid has melted into air (or liquid): a critique of Bauman on individualization and class in liquid modernity”, Sociological Review, 56 (1), pp. 1-17.

BAUMAN, Z. (1982), Memories of class, Londres, Routledge.

BAUMAN, Z. (1989), A liberdade, Lisboa, Editorial Estampa.

BOTTERO W. (2004), “Class identities and the identity of class”, Sociology, 38 (5), pp. 985-1003.

BOTTERO W.; K. Prandy (2003), "Social interaction distance and stratification", British Jounal of Sociology, 54 (2), pp. 177-197.

BOURDIEU, P. (1979), La distinction. Critique sociale du jugement, Paris, Les Éditions de Minuit.

BRADLEY, H. (1996), Fractured identities. Changing patterns of inequality, Cambridge, Polity Press.

DENNIS, N.; F. Henriques (1970) [1956], Coal is our life. An Analysis of a Yorkshire Mining Community, Londres, Barnes \& Noble.

DEVINE, F. (1992), "Social identities, class identity and political perspectives", Sociological Review, 40, pp. 229-252.

DEVINE, F. (2004), “Talking about class in Britain” in F. Divine e M. C. Waters (eds.), Social inequalities in comparative perspective, Oxford, Blackwell, pp.191-213.

DEVINE, F.; M. Savage (2000), “Conclusion: renewing class analysis”, in R. Crompton et al., Renewing class analysis, Oxford, Blackwell.

GIDDENS, A. (1992), As consequências da modernidade, Oeiras, Celta.

GIDDENS, A. (1994), Modernidade e identidade pessoal, Oeiras, Celta.

GOLDTHORPE, J. H.; D. Lockwood et al. (1969), The affluent worker in the class structure, Cambridge, Cambridge University Press.

MARSHALL, G.; D. Rose et al. (1988), Social class in modern Britain, Londres, Routledge.

PAHL, R. (1989), "Is the emperor naked?", International Journal of Urban and Regional Research, 13, pp. 711-720.

PAKULSKI, J. e M. Waters, (1996), The death of class, Londres, Sage.

REAY, D. (1998a), Class work. Mothers' involvement in their children's primary schooling, Londres, Routledge Falmer. 
REAY, D. (1998b), "Rethinking social class: qualitative perspectives on class and gender", Sociology, 32 (2), pp. 259-275.

REAY, D. (2005), "Beyond consciousceness? The psychic landscape of social class", Sociology, 39 (5), pp. 911-928.

SAVAGE, M. (2000), Class analysis and social transformation, Buckingham, Open University Press.

SAVAGE, M. (2001), “Ordinary, ambivalent and defensive: class identities in the Northwest of England", Sociology, 35 (4), pp. 875-892.

SOUTHERTON, D. (2002), "Boundaries of «us» and «them»: class, mobility and identification in a new town", Sociology, 36 (1), pp. 171-193.

SKEGGS, B. (1997), Formations of class and gender, Londres, Sage.

SKEGGS, B. (2004), Class, self, culture, Londres, Routledge.

YOUNG, M. e P. WILLMOTT (1983) [1957], Le village dans la ville, Paris, Centre Georges Pompidou.

\section{RESUMOS}

Há mais de uma década começou a formar-se um movimento de reconversão nos estudos sobre as classes sociais, orientado pela ideia de que é preciso dar mais relevo aos processos culturais, à formação de identidades, ao gosto e à expressão de modos de vida e proceder ao exame direto da maneira como as posições de classe são vividas. Nesta perspetiva, as culturas de classe deixam de designar apenas tipos de comportamento próprios de grupos de desigualdade e passam a ser vistas também como modos de diferenciação, em que as categorias de classe operam através de distinções individualizadas e comparações relacionais com membros de outras classes. 0 que o conceito de identidade de classe quer agora indicar é um sentido das distâncias sociais dentro das hierarquias, que recorre às diferenças culturais para se exprimir. Este texto recenseia os desenvolvimentos teóricos e as bases empíricas desta linha de trabalho, emergente na sociologia britânica a partir do final da década de 90 , com as propostas de autores como Savage, Skeggs, Reay, ou Bottero, entre outros.

More than a decade ago, a small group of social class researchers started looking for new ways of addressing the question of inequality, in a movement guided by the idea that we need to give more thought to cultural processes, the formation of identities, the expression of taste and ways of life, and to examine how class positions are actually performed in everyday social practice. The concept of class culture is no longer attached to specific forms of behavior and is now seen as a mode of differentiation in which categories of class distinction operate through individual and relational comparisons with members of other classes. A class identity becomes a sense of social distance within these hierarchies, which draws on cultural differences to be expressed. This text resumes the theoretical developments and empirical bases of this line of work, emerging in British Sociology since the late 90's, with proposals signed by Savage, Skeggs, Reay, and Bottero, amongst others.

\section{ÍNDICE}

Keywords: social theory, social classes, identities of class

Palavras-chave: teoria social, classes sociais, identidades de classe 


\section{AUTOR}

\section{JOSÉ CAVALEIRO RODRIGUES}

Escola Superior de Comunicação Social - Instituto Politécnico de Lisboa; CRIA - Centro em Rede de Investigação em Antropologia (jrodrigues@escs.ipl.pt) 